Tohoku J. exp. Med., 1965, 85, 286-300

\title{
Stereotaxic Thalamotomy for the Relief of Intractable Pain — CEM-thalamotomy —
}

By

\author{
Miyoshi Urabe and Takashi Tsubokawa
}

\author{
From the Department of Surgery, School of Medicine, University \\ of Kanazawa, Kanazawa
}

(Received for publication, December 28, 1964)

\begin{abstract}
Lesions were made in the nucleus centrum medianum by a stereotaxie technique in 15 cases suffering from intractable pain. The lesion was made unilaterally in 8 and bilaterally in 7 . All of the cases were relieved of intractable pain immediately after the operation without any loss of other sensation. However, unilateral thalamotomy showed a transient effect, while bilateral thalamotomy showed a persistent sufficient effect, for relief of diffuse, poorly localized pain.

There was no operative death or severe complication in this series. After the operation of bilateral CEM-thalamotomy, no change in the EEG was seen. No alteration of consciousness was observed except in 2 cases whose lesion extended to the nucleus parafascicularis or pretectal region.

This operative procedure. CEM-thalamotomy, was an appropriate operation for intractable pain caused by malignant tumor.
\end{abstract}

Stereotaxic operations for the treatment of intractable pain have not yet been commonly accepted, although many trials producing the lesion were done in various regions; the nucleus dorsomedialis (Spiegel and $W y c i s),{ }^{12}$ the nucleus ventralis posterior (Talariach), the nucleus ventralis caudalis parvocellularis (Riechert ${ }^{11}$ ) and the posterior thalamic area (Mark et al. ${ }^{8}$ ). They could not obtain better results than those of bilateral chordotomy at the high cervical level done by White and Sweet. It was mostly caused by the complicated accepting mechanism concerning perception of pain.

Recently there were abundant evidences to indicate that some pathways of transmitting pain did not run through the classical relay nucleus "ventroposterior group" of the thalamus. Bowsher and Mehler et al. ${ }^{10}$ using Nauta's technique, had shown that pain pathways might terminate, via collaterals, in the brain stem reticular formation and in the intralaminar nuclei of the thalamus. Albe-Fessard's' and our experimental ata ${ }^{15}$ showed that the nucleus centrum medianum played an important role in perception of poorly somatized noxious stimuli from the 
periphery.

The authors had operated upon making a circumscribed lesion in the nucleus centrum medianum which was named "CEM-thalamotomy" and they could relieve intractable pain caused by malignant disease. So that, the authors will present the operating method of CEM-thalamotomy and discuss effects and sideeffects of this procedure.

\section{OPERATING METHOD}

The operation was done under local anesthesia after premedication with a small dose of atropine. Stereotaxic instrument manufactured by the authors was used (Fig. 1). This instrument was convenient for observing behavior of the patient and recording the EEG following stimulation of the target point in order to determine position of electrode. A skull incision was made and $2.5 \mathrm{~cm}$ trephine hole was opened. After the dura mater was opened through this hole, the stereotaxic needle was screwed in this trephine. The target point was measured from the posterior commissura which was visualized by radiographic procedure. The nucleus centrum medianum situated in the region where medial border was $4 \mathrm{~mm}$, lateral border $10 \mathrm{~mm}$, superior border $7 \mathrm{~mm}$, inferior border $-1 \mathrm{~mm}$, anterior border $10 \mathrm{~mm}$ and posterior border $2 \mathrm{~mm}$, from the posterior commissura (Fig. 2). Both the distance and angle from the stereotaxic apparatus to the target point were calculated with the scale shown on the apparatus (Figs. 1 and 3). The electrode is inserted into CEM according to these data. Electrode which was inserted through the stereotaxic apparatus was concentric bipolar one insulated with teflon. The electrode was used for both stimu-
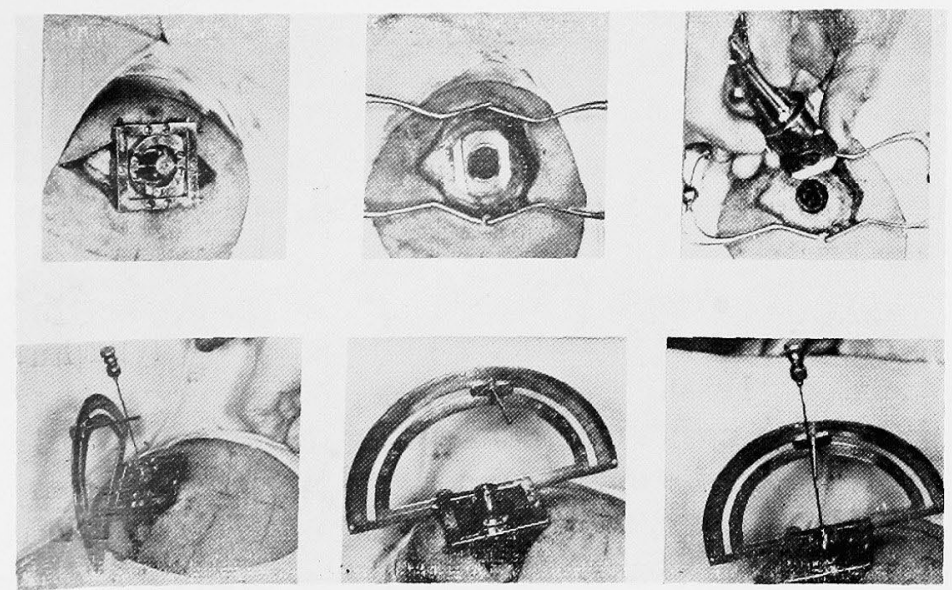

Fig. 1. The stereotaxic apparatus manufactured by the authors which was convenient Ec behavior of the patient and the EEG following stimulation of the thalamus. nance and angle from the stereotaxic apparatus to target point was determined on $t i c$ of the stereotaxic apparatus. 

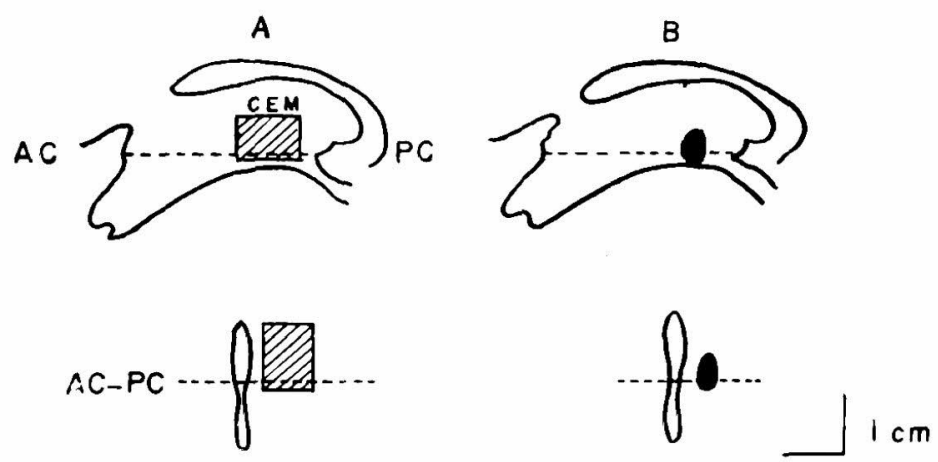

Fig. 2. The nucleus centrum medianum situated in the region where medial border was $4 \mathrm{~mm}$, lateral border $10 \mathrm{~mm}$, superior border $7 \mathrm{~mm}$, inferior border $-1 \mathrm{~mm}$, anterior border $10 \mathrm{~mm}$ and posterior border $2 \mathrm{~mm}$ from the posterior commissure as shown in hatch line area. The target point was shown in B.

$\mathrm{AC}$ : anterior commissure $\mathrm{PC}$ : posterior commissure $\mathrm{CEM}$ : nucleus centrum medianum

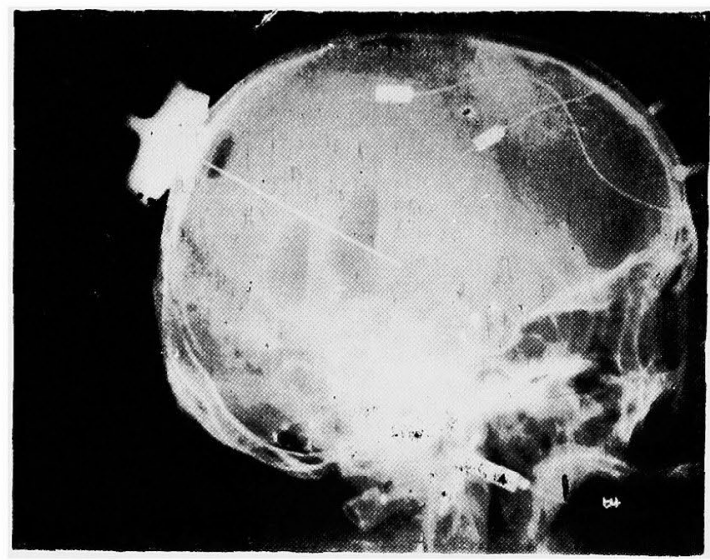

Fig. 3. The electrode was inserted into the nucleus centrum medianum through the stereotaxic apparatus.

lating the target ppint to chek whether its tip reached to the nucleus centrum. medianum and making lesion.

The lesion was produced using electric current of 2 mega cycle, 7.5 watt with 300 ohms load and 100-150 mA through this electrode. The lesion was constantly made as large as a bean (Fig. 4). After making lesion, lipiodol was injected in order to visualize the position of it (Fig. 5).

After the operation, the change of the EEG, the level of consciousness and all types of sensation were examined with routine neurological examination.

An anatomical situation of the lesion was determined by histological pqeppra- 


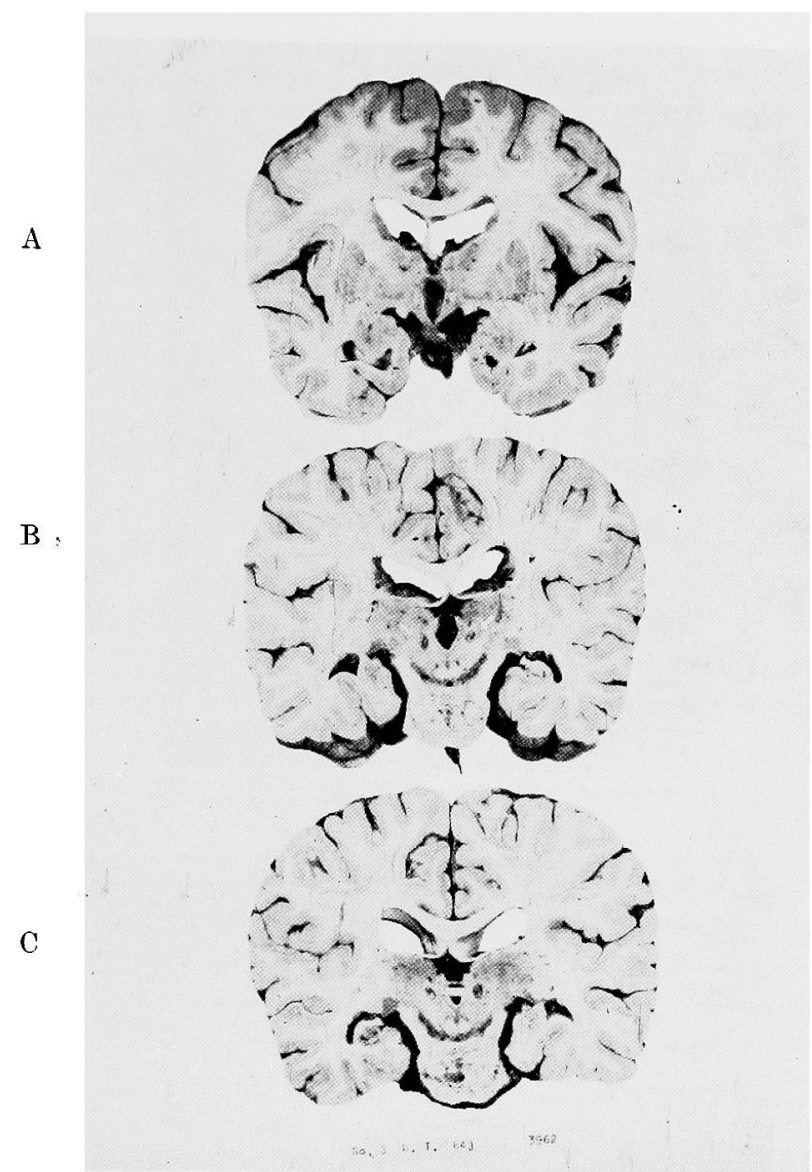

Fig. 4. Case S.I. (63 year-old-man) who succumbed to lung metastasis of rectal cancer after having the bilateral CEM-thalamotomy. Lesions were indicated by white arrows. Each section showed $12 \mathrm{~mm}$ (A), $7 \mathrm{~mm}$ (B) and $2 \mathrm{~mm}$ (C) from the posterior commissure.

tion when the patients died of their malignant tumor after the CEM-thalamotomy.

\section{RESULTS}

CEM-thalamotomy was performed in 15 cases.

The Table I shows 8 cases where CEM-thalamotomy was performed on one side. One of them (M.K.) was a 46-year-old female, suffered from left facial neuralgia. She has had an attack of violent pain on the left retroauricular region since 1960. Prickly pain has been sensible on the posterior wall of the acoustic canal extending toward the neck and shoulder since 1962 . The pain was induced by the chewing movement. Hypesthesia was recognized in the region innervated by the first and second branches of the trigeminal nerve. Impediment of the taste was observed on anterior one-third of the tongue. No 


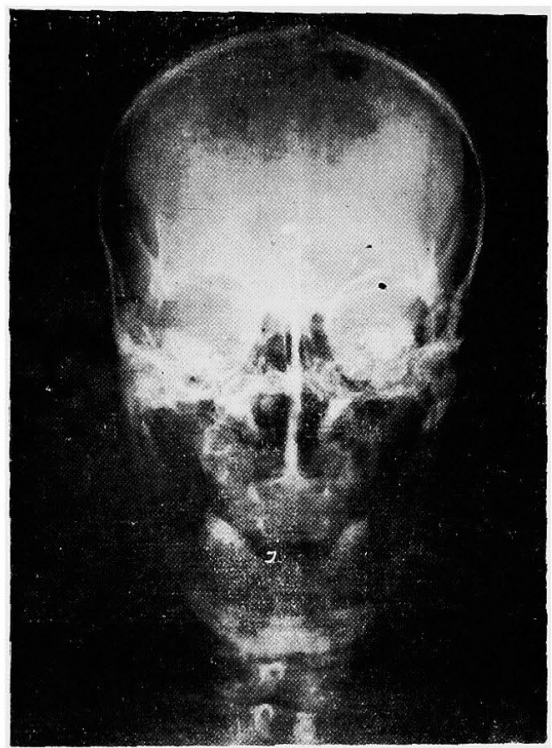

A

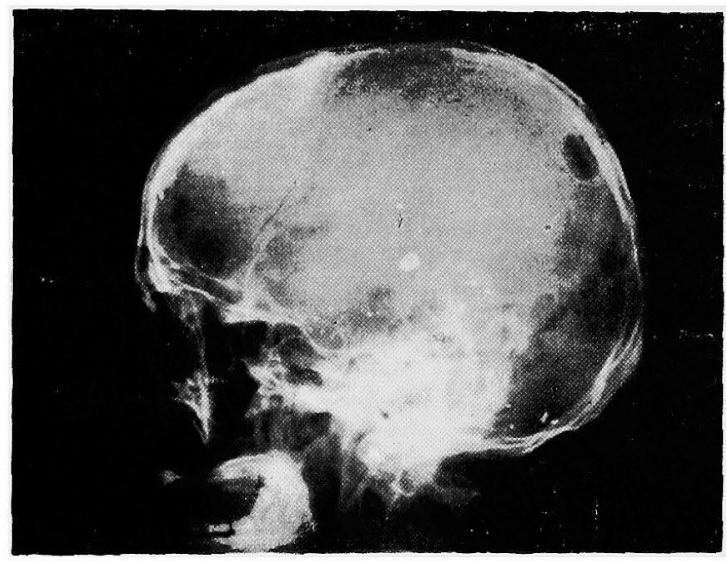

B

Fig. 5. After making lesion in the nucleus centrum medianum, lipiodol was injected into the lesion in order to visualize the position of it.

A: posterior-anterior view B: left-right view

change was seen in the examinations of blood, urine and cerebrospinal fluid. Roentgenogram of the skull, cerebral angiogram and ventriculogram showed no particular finding. Diagnosis was made as the left intermedial neuralgia. Retrogasserian rhizotomy was done without effect for relief of pain. Then, right CEM-thalamotomy was operated upon, making circumscribed lesion in the contralateral nucleus centrum medianum. She was completely relieved from 
Stereotaxic Thalamotomy for the Relief of Pain

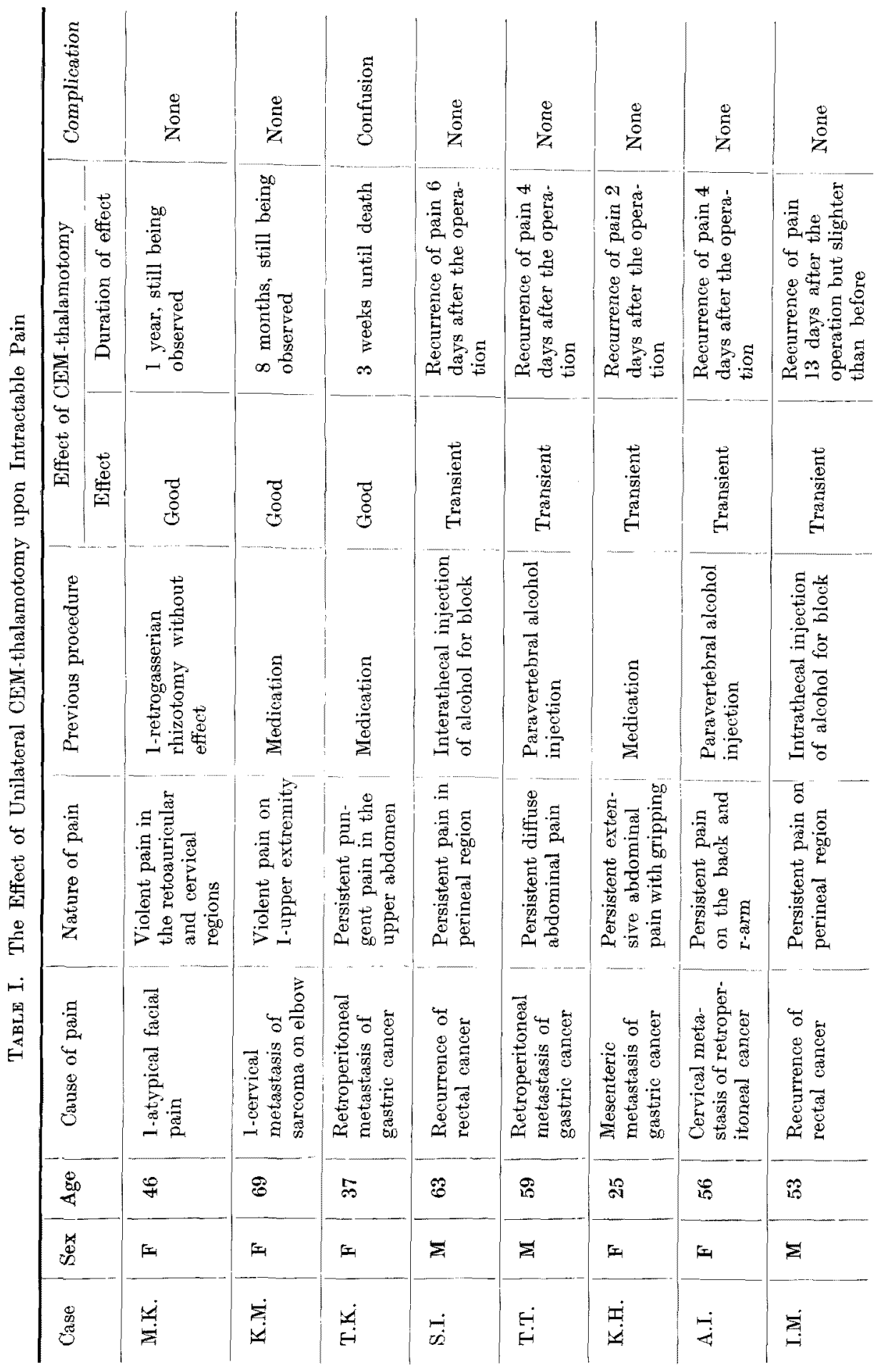




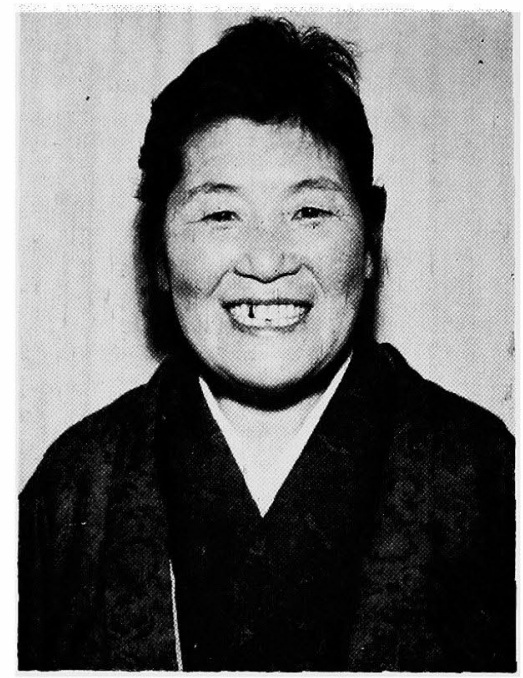

Fig. 6. Case M.K. (46-year-old woman), who suffered from left atypical facidl pain not relieved by retrogasserian rhizotomy, could be relieved by right CEM-thalamotomy. She is enjoying her life and engages in hauskeeper.

violent pain immediately after the operation. Pain sensation following pin-prick stimulus also disappeared on the left side of the whole body. Hypesthesia of all types of somatic sensation on the contralateral side of the lesion was observed for 1-3 days after the operation, which completely recovered thereafter. The consciousness was always kept clear and the EEG was also normal after the operation (Fig. 7). In further course, the intractable pain never recurred, though hypalgesia following pin-prick stimulation returned to the normal state. The patient has completely been relieved from the intractablepain for 1 year after the operation until the present time. She is enjoying her life (Fig. 6).

The case K.M. was a 69-year-old female, suffered from intractable pain of the left upper extremity caused by cervical metastasis of sarcoma on the left ulna. She was relieved from pain immediately after making lesion in the contralateral nucleus centrum medianum. Hypesthesia of somatic sensation was recognized on the contralateral side of the lesion for 1-3 days after the operation, but it was recovered gradually. Though hypalgesia to the pin-prick stimulation returned to the normal state a few days, the intractable pain sensation never recurred and the patient has been relieved from pain for 8 months until the present time.

The case, T.K. was a 37 -year-old female who had intractable pain in the right upper abdomen caused by retroperitoneal metastasis of gastric cancer. The CEM-thalamotomy on one side exhibited an effect to be relieved from violent pain for 3 weeks after the procedure until death of cancer. However, in this case somnolence with confusion was observed after the operation and the EEG 


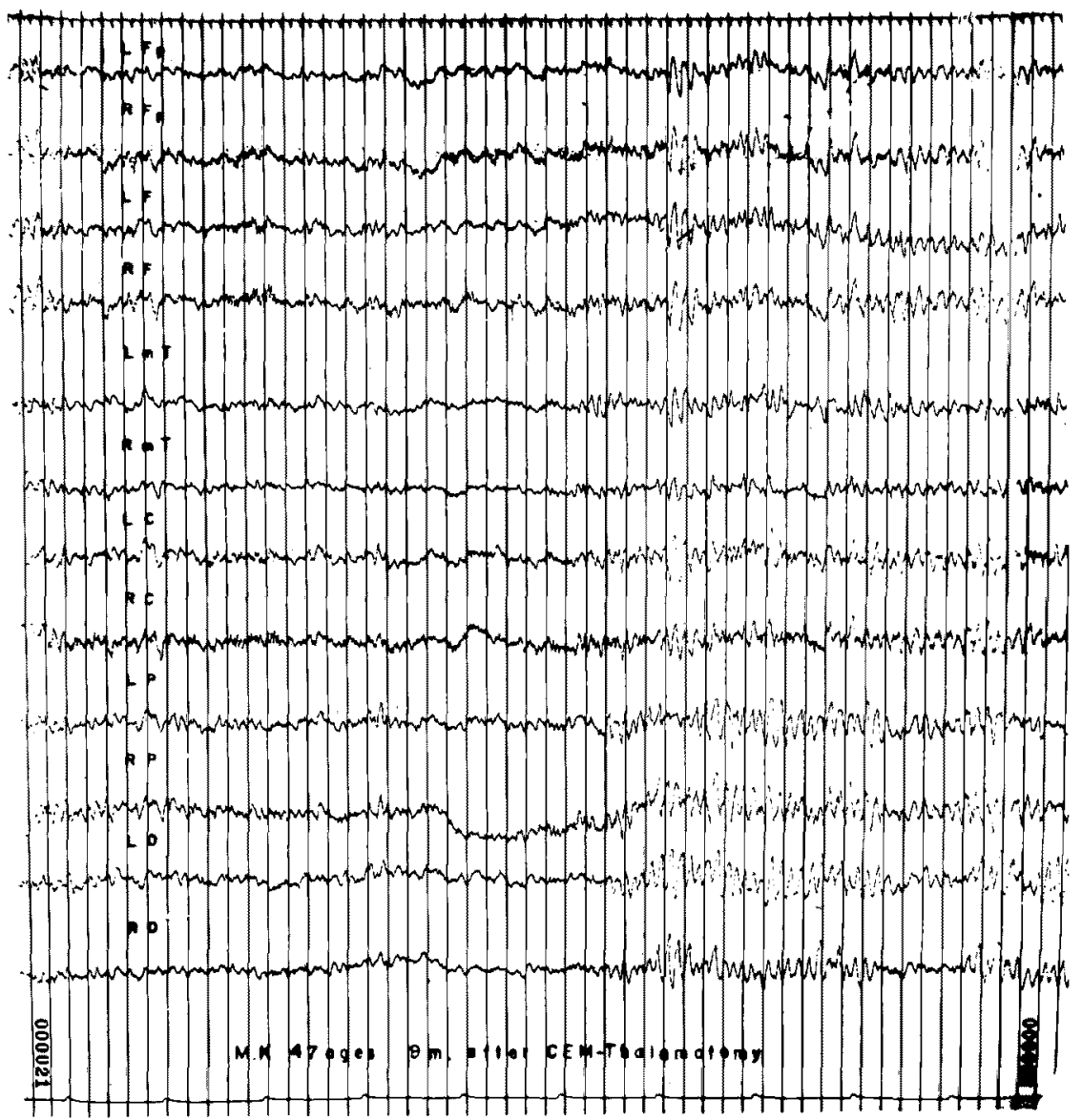

Fig. 7. Case M.K. (46 year old woman). The EEG at 9 months after right CEMthala motomy.

The consciousness was always kept clear and the EEG was also not changed.

showed periodically recurring slow waves without focal pattern. The autopsy revealed that the lesion involved the nucleus parafasicularis. It penetrated to the third ventricle and caused ependimitis of the ventricle (Fig. 8).

In other 5 cases, S.I., T.T., K.H., A.I., and I.M. who had intractable pain in abdominal, thoracic or lumbar area caused by metastasis or recurrence of gastric, rectal or retroperitoneal cancer, a lesion was made at the nucleus centrum medianum on one side. The effect was transient and their intractable pain recurred in a few days after the operation, though no any complication was shown. The pain in these cases was not localized and no laterality of pain sensation was seen.

So that, bilateral thalamotomy should be performed for the patients who had 


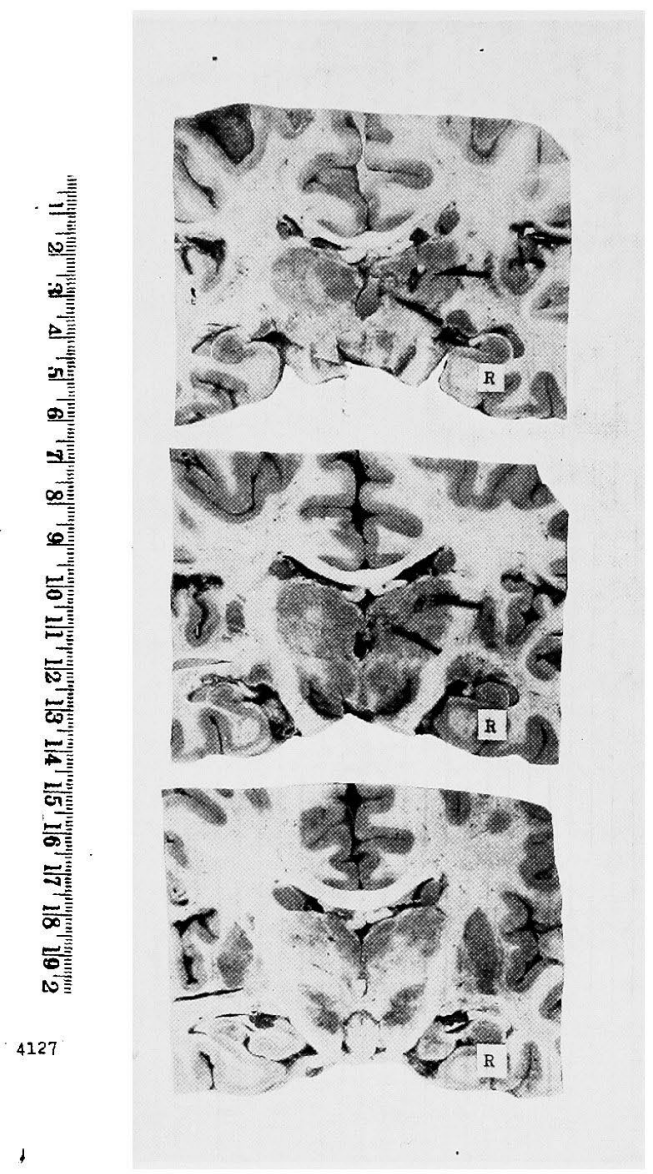

Fig. 8. Case T.K. (37-year-old female), who suffered from intractable pain caused by retroperitoneal metastasis of gastric cancer. She was relieved from pain after the CEMthalamotomy but showed somnolence with confusion and the EEG showed periodically recurring slow wave without focal pattern. The lesion involved the nucleus parascicularis and dorsomedialis. And it penetrated to the third ventricle resulting in ependymitis of the ventricle. The lesion was indicated by black arrow.

diffuse intractable pain. That is, for 7 cases who had diffuse intractable pain, having no laterality, caused by metastasis of carcinoma, bilateral CEM-thalamotomy was operated upon as shown in Table II. All of the cases were completely relieved from the intractable pain immediately after the operation. The effect was persisted for long period until the patients died of malignant disease or the effect was recognized for more than 2 months after the operation, the patients being still observed at the present time.

Hypesthesia of cutaneous sensation of various modalities was observed on the entire area of the body for 1-5 days after the bilateral thalamotomy, until it 
Stereotaxic Thalamotomy for the Relief of Pain

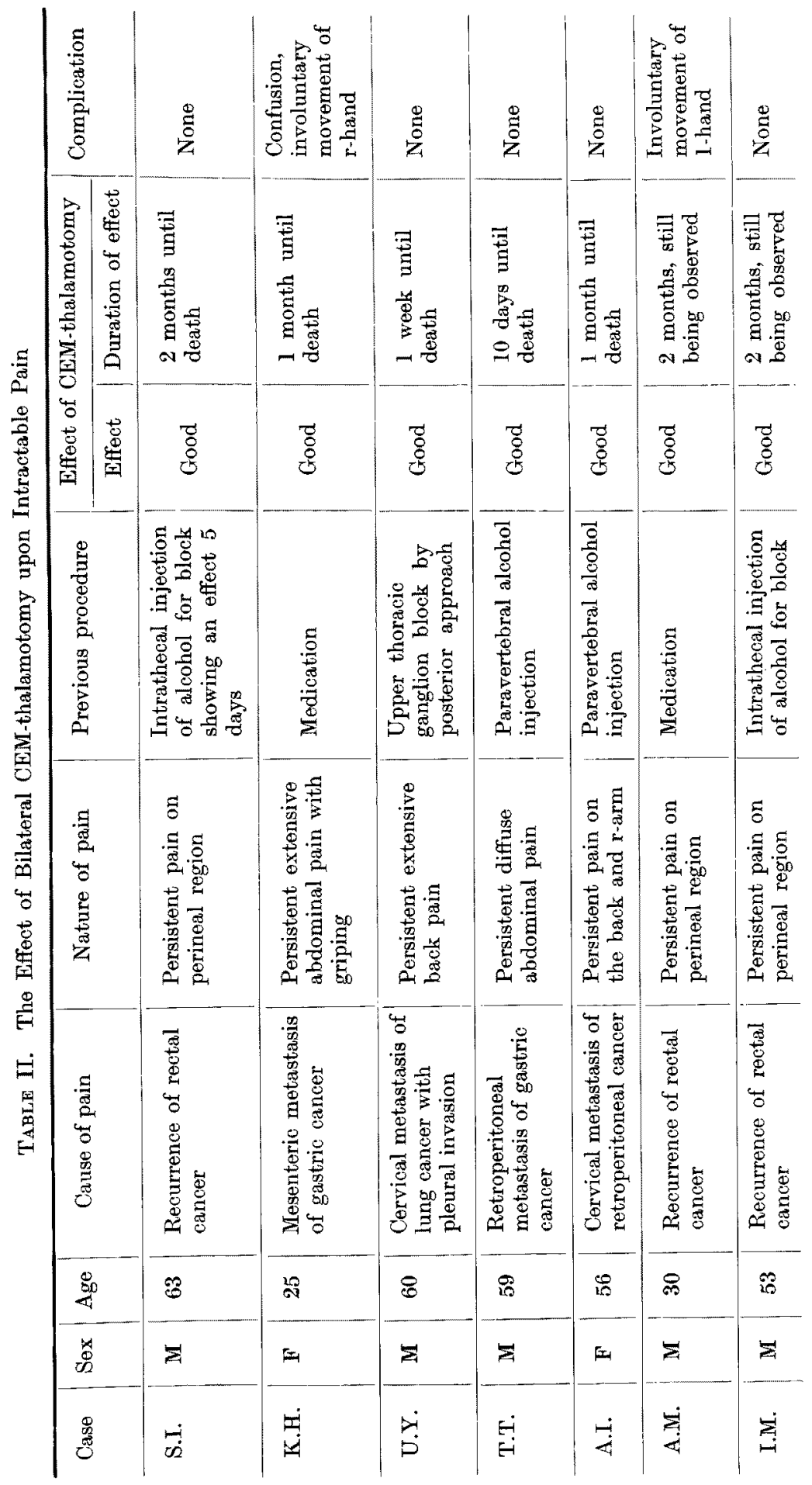




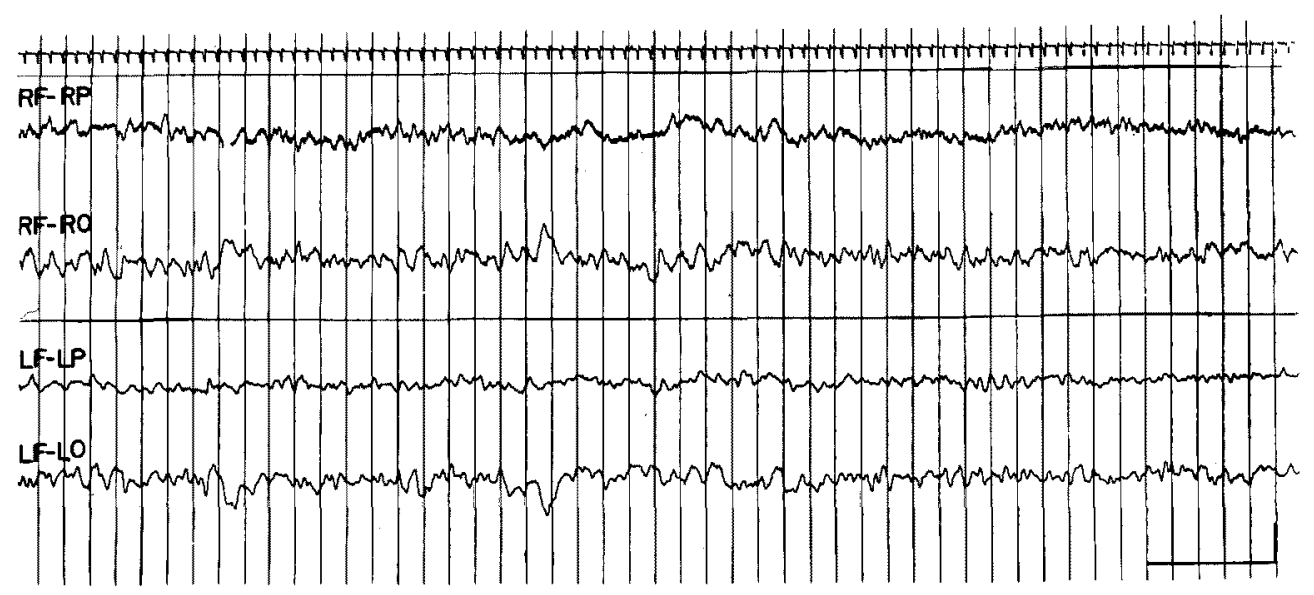

Fig. 9. Case U.Y. (60-year-old man), who suffered from intractable pain caused by cervical metastasis of lung cancer. The EEG recorded immediately after bilateral CEM-thalamotomy. No change was detected. Calibration: $50 \mu \mathrm{V}, 1$ sec.

was completely recovered. Hypalgesia to the pin-prick stimulus was also recognized for 3-50 days until it returned to the normal state, though the intractable pain sensation nerver recurred. So that, there was no relationship between the recurrence of intractable pain and the return from hypalgesia following the pinprick stimulation.

The level of consciousness and the EEG did not show any change after bilateral CEM-thalamotomy, so far as the lesion was localized in the nucleus centrum medianum (Fig. 9).

Concerning the complication of the operation, one case, K.H. had confusion. In this case, it was revealed by autopsy that bilateral lesion extended to the pretectal area. Two cases, K.H. and A.M. whose lesions were too deep extending to the red nucleus, had transient involuntary movement with a little weakness after the operation. However, there was no any complication caused by this operation if the lesion localized in the nucleus centrum medianum. Operative death was not experienced in the case of thalamotomy.

\section{DISCUSSION}

The correlation of the lesion site with the clinical manifestation produced by thalamotomy has been observed by Hecaen et al., ${ }^{6}$ Spiegel and Wycis, ${ }^{12}$ Torvik, ${ }^{13}$ Bettga and Yoshida ${ }^{2}$ and Mark et al. ${ }^{8}$ These authors mostly made lesion at the relay nucleus of the classical spinothalamic pathway. They could not get better results than those of the chordotomy at the high level of the spinal cord.

The experimental data recently described by Bowsher, ${ }^{3}$ Mehler et al. ${ }^{10}$ Mountcastle, ${ }^{9}$ Albe-Fessard and Kruger and the present authors ${ }^{15}$ have shown that pain 
pathway might ascend via collaterals in the brain stem reticular formation and in the intralaminar nucleus of the thalamus. According to these data, it was suggested that the spinothalamic system was responsible for the type of pain which was sharply localized and lasted only for as long as the provoking stimulus was applied, while the spino-reticular or intralaminar nucleus system was responsible for diffuse, poorly localized pain which persisted even after the withdrawal of the irritating stimulus.

It was very difficult to make the lesions in the brain stem without any complication. Wycis and Spiege ${ }^{14}$ operated upon to destroy the spinothalamic tract at the midbrain with $7.4 \%$ of operative mortality and experienced severe complications though they operated using their excellent stereotaxic apparatus. Hassler and Riechert ${ }^{5}$ and Bettag and Yoshida ${ }^{2}$ made lesion for relief of pain in a little lateral region of the sensory relay nucleus which should be a subdivision of the pain system, nucleus dorsomedialis in the thalamus. But the recurrence of intractable pain was observed in $97 \%$ of all cases (Bettag and Yoshida). Observing anatomically the thalamic lesion in 11 cases, Mark et al. ${ }^{8}$ suggested that characterized sensory loss with a mediocre relief of pain was seen when the chief anatomical lesion was made in the sensory relay nucleus. However, the syndrome including little or no sensory loss with an effective relief of pain was observed when cheif lesion was made in the intralaminar nucleus. Although they made too big lesions to identify localization exactly, their results could confirm Mark's concept. Based on these facts, it was assumed that the pain transmission system was very different between the intractable visceral pain sensation and somatic pain sensation.

Our CEM-thalamotomy could be performed on very poor risk patients who could not undergo anterolateral tractotomy without any complication. Ten of our cases would need bilateral operations, if chordotomy, to relieve their intractable pain. White and Sweet reported that good result was obtained in $72 \%$ of the cases of bilateral chordotomy, ineffectiveness was shown in $7.7 \%$, motor paralysis was seen in $15 \%$ and disturbance of micturition was recognized in all the cases. On the other hand, CEM-thalamotomy exhibited a sufficient effect for complete relief of intractable pain without any severe complication. So that, the CEM-thalamotomy was more appropriate operation than the chordotomy, in the case of intractable pain or facial and cervical neuralgia.

Concerning complication of the lesion located in the nucleus centrum medianum, Hecaen et al., ${ }^{6}$ who made lesion in both the nucleus posteroventralis medialis and the nucleus centrum medianum, reported dead cases by functional ileus. And they suggested that the disturbances of autonomic nervous system were caused by the lesion of the nucleus centrum medianum. However, according to our result, there was neither functional ileus nor vomiting following a circumscribed lesion in this nucleus. Two of our cases had involuntary movement. 
But their lesion extended to the red nucleus. To prevent this complication, we now insert the electrode via the occipital area. One of the functions of the medial thalamus may be the maintenance of consciousness (Magoun ${ }^{7}$ ). However, in our cases, lesions located in the nucleus centrum medianum did not produce any change of consciousness. And no any abnormal neurological manifestation was recognized by routine examination and the EEG. Therefore, CEM-thalamotomy caused no any hazard, so far as the lesion was localized in the nucleus centrum medianum.

It is significant result of this study that stereotaxic thalamotomy with the making of a circumscribed lesion in the nucleus centrum medianum could completely relieve intractable pain with little or no sensory loss and without any complication.

\section{References}

1) Albe-Fessard, D. \& Kruger, L. J. Neurophysiol., 1962, 25, 3.

2) Bettag, W. \& Yoshida, T. Acta neurochir., 1960, 8, 297.

3) Bowsher, D. Brain, 1957, 80, 606.

4) Ervin. F.R. \& Mark. V.H. Arch. Neurol., 1960, 3, 368.

5) Hassler, R. \& Riechert, T. Arch. Psychiat. Nervenkr., 1953, 200, 93.

6) Hecaen, H., Talairach, J., David, M. \& Dell, M.B. Rev. Neurol., 1949, 81, 917.

7) Magoun, H.W. The Waking Brain, C.C. Thomas, Springfield, 1958.

8) Mark, V.H., Ervin, F.R. \& Yakovlev, P.L. Arch. Neurol., 1963, 8, 528.

9) Mountcastle, V.B. Sensory Communication, Editor. W.B. Rosenblith. The M.I.T. Press Boston, 1961, p. 403.

10) Mehler, W.H., Feferman, M.E. \& Nauta, W.J.H. Brain, 1960, 718.

11) Riechert, T. German medical monthly, 1962, 7, 259.

12) Spiegel, E.A. \& Wycis, H.T. J. Amer. med. Ass., 1952, 148, 446.

13) Torvik, A. J. Neurol. Neurosurg. Psychiat., 1959, 22, 299.

14) Wycis, H.T. \& Spiegel, E.A. J. Neurosurg., 1952, 10, 101.

15) Urabe, M., Tsubokawa, T., Watanabe, Y. \& Kadoya S. Jap. J. Physiol., 1965, 15, 28. 